\title{
EMOCIONES CON VIDEOJUEGOS: INCREMENTANDO LA MOTIVACIÓN PARA EL APRENDIZAJE
}

Resumen: Las emociones pueden influir positiva o negativamente en el aprendizaje y sobre todo en la motivación para aprender. Lograr que un alumno se sienta o no motivado a aprender "algo" es una de las claves del aprendizaje autónomo. Por ello, en este artículo se presenta el diseño y experimientación de un prototipo de videojuego 3D integrado en un aula virtual con alumnos universitarios, con el fin de estudiar cómo las emociones despertadas por los videojuegos pueden influir positiva o negativamente en la motivación hacia el aprendizaje. Hemos sustentado nuestra investigación en teorías correspondientes a interfaces afectivas, aprendizaje colaborativo apoyado con ordenadores (CSCL) y videojuegos; mientras que en el planteamiento metodológico del diseño y validación, hemos utilizado los fundamentos de la disciplina IPO (Interfaz Persona-Ordenador), en concreto, los principios del diseño centrado en el usuario (DCU). En la evaluación se ha analizado por qué se producían las emociones y por qué consideraban que incrementaba o no la motivación hacia la asignatura. Los resultados obtenidos indican que no sólo la motivación es beneficiosa para el aprendizaje, sino que también la frustración producida por los videojuegos puede ser utilizada para lograr una mayor persistencia en los logros de los objetivos de aprendizaje. Asimismo, descubrimos algunos problemas en la percepción de lo lúdico como una actividad de aprendizaje en la enseñanza superior.

Palabras clave: Juegos de rol, Videojuegos, Interfaces emocionales, Motivación

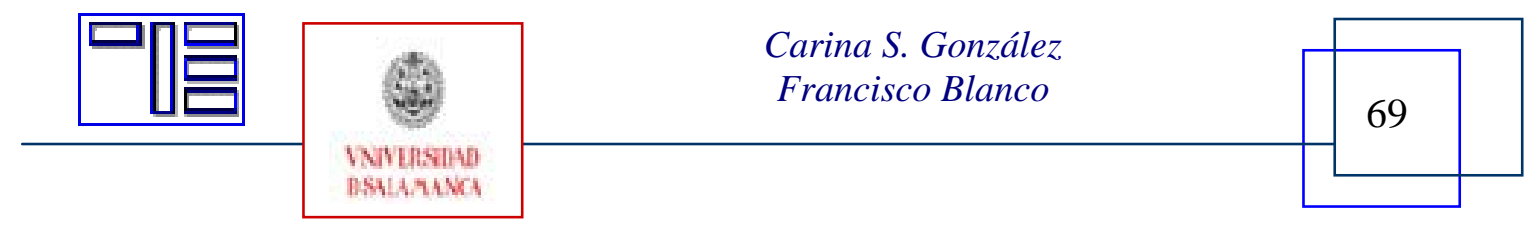




\section{EMOTIONS WITH VIDEOGAMES: INCREASING THE MOTIVATION TO LEARN}

Abstract: Emotions can influence the learning in a positive or a negative way, especially in the motivation to learn. Have a student motivated or not to learn "something" is one of the autonomous learnig keys. For that reason, in this article we present the design and experimentation of a $3 \mathrm{D}$ videogame prototype integrated into a virtual classroom with university students with the aim of analyse how the emotions produced by videogames can influence positive or negatively on the motivation to learn. We have support our research on theories regarding to afective interfaces, computer support colaborative learning (CSCL) and videogames; meanwhile for the desing, development and evaluation methodology we have used the guide of Human Computer Interaction (HCI) area. In particular, we have followed the User Centered Design (UCD) principles. In the evaluation, we have analized the reasons of the motivation and its influence to the positive actitude on the subject. The results of evaluation shows that not only the motivation can be used positively in the learning, but frustation also, for example, can be used to produce a major persistence in the achivemment of learning goals. On the other hand, we found some problems in the perception of ludic things as a learning activity in high levels of teaching, such as univercity students.

Keywords: Role playing game, Videogames, Emotional Interfaces, Motivation

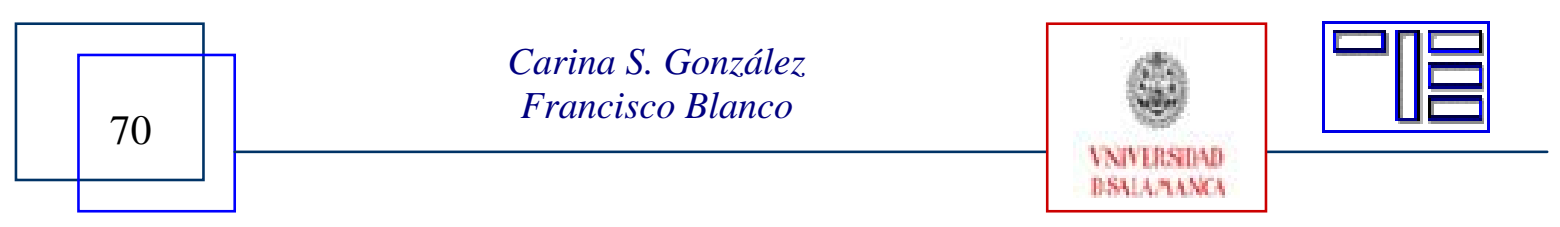




\section{ÉMOTIONS AVEC JEUX VIDEO: AUGMENTANT LA MOTIVATION POUR L'APPRENTISSAGE}

Sommaire: Les émotions peuvent influencer positivement ou négativement l'apprentissage et surtout la motivation pour l'apprentissage. Obtenir qu'un élève s?asseye ou non motivé à apprendre "quelque chose " est l?une des clés de l'apprentissage autonome. Pour cela, dans cet article on présente la conception et l'expérimentation d'un prototype de jeu vidéo 3D intégré dans une salle de classe virtuelle avec des élèves universitaires, afin d'étudier comment les émotions suscitées par les jeux vidéo peuvent influencer positivement ou négativement la motivation à l'apprentissage. Nous avons fondé notre recherche sur des théories correspondantes à des interfaces affectives, apprentissage collaboratif basé sur ordinateur (CSCL) et jeux vidéo ; tandis que dans l'approche méthodologique de la conception et la validation, nous avons utilisé les fondements de la discipline IPO (Interface Personne-Ordinateur), concrètement, les principes de la conception centrée sur l'utilisateur (DCU). Lors de l'évaluation, nous avons analysé pourquoi les émotions se produisaient et pourquoi les étudiants considéraient que la motivation vers la matière augmentait ou non. Les résultats obtenus indiquent que non seulement la motivation est bénéfique pour l'apprentissage, mais aussi la frustration produite par les jeux vidéo peut être utilisé e pour obtenir une plus grande persistance dans l?atteinte des objectifs d'apprentissage. De même, nous découvrons quelques problèmes dans la perception du ludique comme une activité d'apprentissage dans l'enseignement supérieur.

Mots Clés: Jeux de rôle, Jeux vidéo, Interfaces émotionnelles, Motivation.

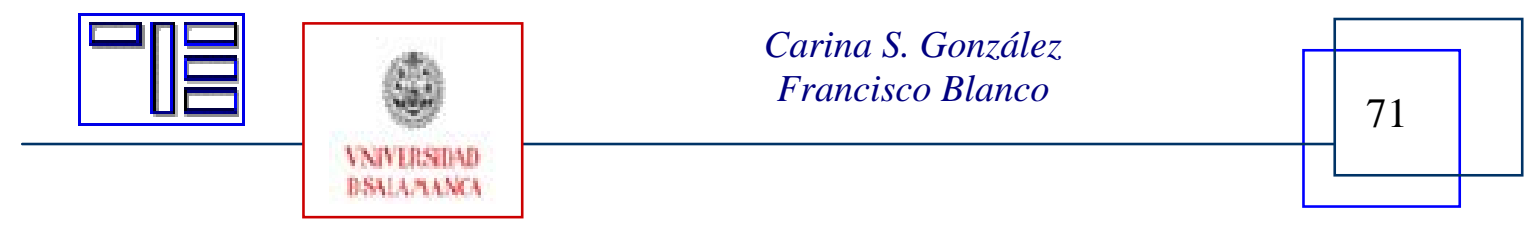




\section{EMOCIONES CON VIDEOJUEGOS: INCREMENTANDO LA MOTIVACIÓN PARA EL APRENDIZAJE}

Carina S. González.

Francisco Blanco

carina@isaatc.ull.es

Universidad de La Laguna

Unidad para la Docencia Virtual

\section{1.- INTRODUCCIÓN}

El documento que presenta el trabajo realizado por el Grupo de Investigación sobre Videojuegos de la Universidad de Málaga, dentro de la "Serie Informes": Investigación en Tecnologías de la Información y Comunicación para la Educación del CNICE, recoge ampliamente el estado de la investigación actual sobre videojuegos y educación, especialmente en España. Según este informe, mientras el discurso social descalifica a los videojuegos, los estudios científicos sobre los efectos de los videojuegos constatan la práctica inexistencia de efectos negativos, junto a la existencia de algunos positivos, entre otros, los de tipo instructivo. Por otro lado, los juegos educativos se perciben con un alto potencial educativo por su carácter motivador (Foreman, 2004; Squire, 2006).

La razón por la cual los videojuegos nos atraen tanto está en que poseen lo que en psicología se denomina "factores dinamizadores de nuestra conducta". En otras palabras, los videojuegos poseen el suficiente atractivo o despiertan la suficiente motivación como para que los niños y jóvenes se sientan conectados a su dinámica interna. Esta dinámica incluye un carácter lúdico y entretenido, junto a un alto valor en estimulación auditiva, kinestésica, visual, etc., y la incorporación de niveles de dificultad progresivos y graduales que requieren el dominio de los anteriores. Algunos factores dinamizadores de la conducta son: las situaciones que supongan retos continuos y que precisen de una constante superación personal; las situaciones de competitividad (generadas no sólo por el propio desarrollo del juego, sino también por la situación de enfrentamiento con otros compañeros); y la existencia de incentivos, que hace que el papel de la autoestima se acreciente a medida que los objetivos propuestos se obtienen.

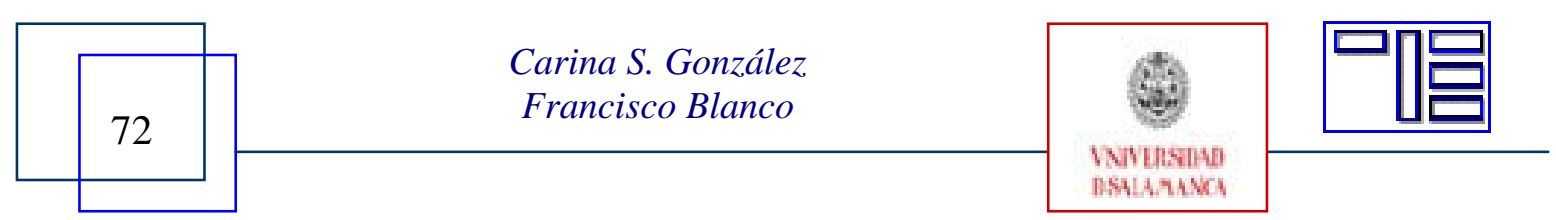


Por otra parte, la psicología cognitiva nos dice que los factores humanos (atención, motivación, memoria, emociones, etc.) afectan a la interacción con los ordenadores. Debido los efectos positivos demostrados y sobre todo al efecto motivador, en este trabajo nuestro objetivo es analizar la manera en que los usuarios interactúan para lograr las metas propuestas dentro de un videojuego, estudiar los factores emocionales que han intervenido en el proceso y como impactan en la motivación para aprender. Para ello, se ha diseñado e implementado un prototipo de videojuego conectado a Moodle, considerando los aspectos emocionales y cognitivos, así como el trabajo en grupo. Para poder diseñar una interfaz que tuviera en cuenta los factores humanos, hemos seguido los lineamientos del área de Interacción Persona-Ordenador (IPO), que estudia al usuario, sus interacciones y roles, dentro de un contexto, con otros usuarios y con el ordenador. En concreto hemos utilizado la metodología de Diseño Centrado en el Usuario (DCU) (Maguire, 2001; Shneiderman, 1992, 1998). Además, hemos fundamentado este trabajo en ideas provenientes de diversas teorías de Interfaces Afectivas (Paiva, 2000; Picard, 1997; de Vicente, 2003; del Soldato y du Boulay, 1996, Elliott; 1992; Issroff y del Soldato, 1996), Aprendizaje colaborativo basado en ordenadores ó CSCL (Barros, 1999; Moreno y otros, 2007; Gee, 2003; Burgos, 2007).

En este artículo se presenta, en primer lugar una breve introducción al marco teórico sobre la evolución de internet, los videojuegos, sus usos educativos y los factores emocionales considerados; luego se describe el proceso de diseño del prototipo funcional implementado utilizando la metodología DCU, así como las actividades llevadas a cabo en el aula de informática con alumnos universitarios, con los que hemos analizado los factores emocionales y su impacto en la motivación para el aprendizaje. Finalmente, se presentan los resultados obtenidos y las conclusiones extraídas.

\section{2.- EVOLUCIÓN DE INTERNET, VIDEOJUEGOS Y EDUCACIÓN}

Cuando hablamos del futuro de Internet pensamos en la "red semántica”, más inteligente, con bases de datos distribuidas, procesamiento del lenguaje natural y agentes autónomos (Spivak, 2006). Aunque existan desarrollos al respecto, todavía queda camino por recorrer para llegar a esta red inteligente o Web 3.0. Sin embargo, la que ha sido llamada Web 2.0 o Web social de lecto-escritura ya está aquí, soportándose en las redes sociales, los blogs, los wikis y la compartición de recursos multimedia. Otra realidad es la llamada Web 3D y sobre estos entornos y sus implicaciones haremos énfasis en este trabajo.

Para guiar el desarrollo de esta web 3D existen ya instituciones como la Web3D Consortium, ligado al W3C que promueve el X3D, un estándar libre de franquicia para formatos de fichero y una arquitectura para representar y comunicar escenas 3D y objetos usando XML. El estándar está ratificado por la ISO y proporciona un sistema para almacenar, recuperar y reproducir contenidos en 3D en tiempo real incrustado en otras aplicaciones, todo ello con una arquitectura abierta que soporta una amplia variedad de dominios y escenarios de uso.

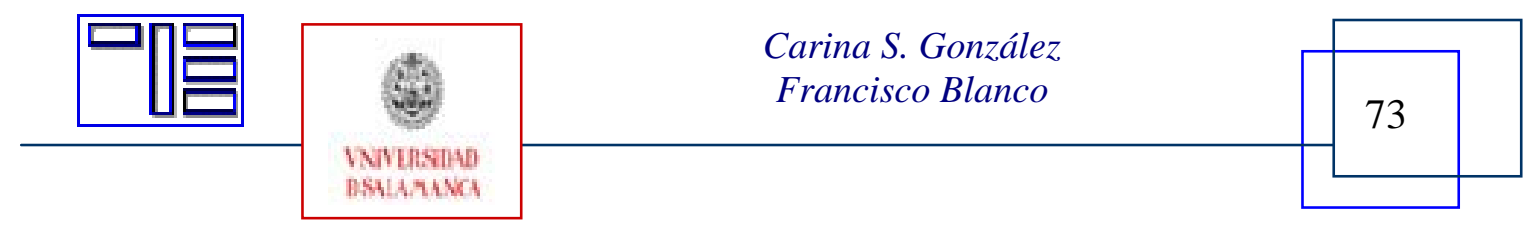


Sin duda, el impacto del juego "Second Life" ha contribuido notablemente a la Web 3D, hasta el punto de que es rara la semana en la que no aparece en la prensa una noticia relacionada con el juego de ordenador "Second Life", que pueden estar referidas por ejemplo a una importante empresa multinacional que ha inaugurado su sede en este mundo virtual, o un político que ha dado un mitin a los ciudadanos usando este medio o un empresario que ha ganado una importante suma vendiendo determinado objeto virtual.

Podríamos decir que Second Life (SL) formaría parte de una categoría de juegos denominada MMORPG (Multiuser Massive Online Role Play Game). Un MMORPG es un tipo de juego en el que un gran número de jugadores, típicamente del orden de miles, interactúan entre ellos por medio de personajes en el contexto de un entorno tridimensional. En SL no existe un argumento definido, sino que se crea un mundo virtual alternativo llamado "metaverso" que los jugadores pueden construir conforme van jugando. En este "metaverso" los jugadores interactúan por medio de avatares, socializando, comerciando, etc. Aunque SL es el más conocido de estos metaversos, no es el único.

Muchos autores creen que ésta será la forma predominante de estar online, relacionarse, acceder a información y acordar transacciones comerciales y por tanto que constituyen la primera fase de una nueva Internet. Cuando estas interacciones se producen en un entorno telemático, podemos hablar de "comunidad virtual”.

Es bien conocido que la interacción social favorece el proceso de aprendizaje, ya que produce conflictos cognitivos mediados por la discusión y el intercambio de opiniones que fuerzan a la reflexión y cambio cognitivo. El intercambio de informaciones entre personas que tienen diferentes niveles de conocimientos provoca una modificación de los esquemas de los individuos que produce aprendizaje (Carretero, 2004). Entonces podemos definir a una "comunidad de aprendizaje virtual" como un grupo de personas que concurren en un espacio de encuentro virtual para, haciendo uso de un conjunto de recursos telemáticos, establecer acciones comunicativas de carácter interactivo que les permitan alcanzar unos objetivos comunes de aprendizaje. En este punto es interesante distinguir entre la base tecnológica que posibilita este aprendizaje (entorno colaborativo de aprendizaje) y la propia comunidad (Barberá, 2004). No obstante, sólo por trabajar en grupo, no se garantiza que se produzca aprendizaje colaborativo. Es necesario definir el contexto y que se empleen las metodologías adecuadas garantizando el cumplimiento de cinco pautas: 1) Interdependencia positiva, 2) Interacción cara a cara, 3) Responsabilidad individual y de grupo, 4) Aprendizaje de habilidades sociales, 5) Revisión del proceso del grupo.

\section{3.- ¿PUEDEN AYUDARNOS LOS VIDEOJUEGOS A APRENDER?}

La percepción de la potencialidad educativa de los videojuegos proviene de la idea de asociar determinados tipos de videojuegos con el fomento de algunas capacidades. Podemos citar a Estallo (1994, 1995), Calvo (2000), Gros (1997, 2000), Etxebarría (1998)

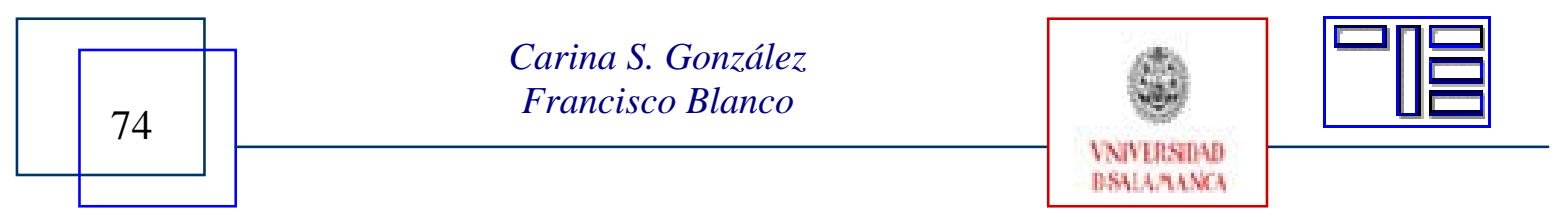


y Marqués (2000), como algunos de los investigadores españoles que promueven esta idea. Según Estallo (1994,1995), los videojuegos pueden contribuir al desarrollo tanto emocional como intelectual de los adolescentes. Por otra parte, Marqués (2000) asocia cada tipo de juego con una serie de habilidades y capacidades de desarrollo de interés para el aprendizaje. Por ejemplo, los juegos de arcade (plataformas, luchas...) pueden contribuir al desarrollo psicomotor y de la orientación espacial; los deportivos, a la coordinación psicomotora; aventura, estrategia y rol, a la motivación para temas del currículum y a la reflexión sobre sus valores; los simuladores, al funcionamiento de máquinas; y los puzzles y de preguntas, al razonamiento y a la lógica. Entre los aspectos positivos de aprendizaje Marques (2000) señala: la motivación, el aprendizaje de contenidos y tareas, los procedimientos y destrezas manuales/organizativas, y las actitudes como la toma de decisiones y la cooperación.

Por otra parte, en "What Videogames have to teach us about learning and literacy" James Paul Gee (2003) sostiene que los buenos videojuegos son "máquinas para aprender” puesto que incorporan algunos de los principios de aprendizaje más importantes postulados por la ciencia cognitiva actual. En concreto señala:

- Los buenos videojuegos proporcionan a los usuarios información bajo demanda $\mathrm{y}$ en el momento en el que la necesitan, no fuera de contexto como ocurre frecuentemente en las aulas. A las personas nos resulta mucho más difícil recordar o entender información que nos es dada fuera del contexto de uso, o mucho antes de usarla. (Barsalou, 1999; Brown y otros, 1989; Glemberg y Robertson, 1999).

- Los buenos juegos son capaces de enfrentar a los usuarios a tareas que constituyen retos pero al mismo tiempo son realizables. Esto es fundamental para mantener la motivación a lo largo de todo el proceso de aprendizaje.

- En los buenos juegos convierten a sus usuarios en creadores, y no en meros receptores. Sus acciones influencian o construyen el universo de juego.

- Los buenos juegos enfrentan a los jugadores a unas primeras fases específicamente diseñadas para que adquieran conocimientos básicos que les permitan construir generalizaciones y enfrentarse a problemas más complejos.

- Los buenos juegos crean el “ciclo de la maestría” (Bereiter y Scardmalia, 1989), que hace que los jugadores adquieran rutinas que les llevan a mejorar su nivel para hacer una tarea concreta. Cuando cierta tarea es dominada, se presentan tareas más difíciles que vuelven a iniciar el ciclo.

Muchas de estas ventajas tienen que ver con características de los juegos y no necesariamente con el hecho de que sean juegos. Por ello, muchas de esas características pueden ser usadas en el aprendizaje de contenidos y habilidades en las escuelas y trabajos. Tradicionalmente, y aun hoy en día, el enfoque usado casi siempre para usar los videojuegos con fines educacionales ha sido elaborar videojuegos específicamente diseñados para ese fin. La lista de títulos de este tipo sería innumerable, pero podemos afirmar sobre ellos que en casi todos los casos han sido elaborados con bajos presupuestos. En

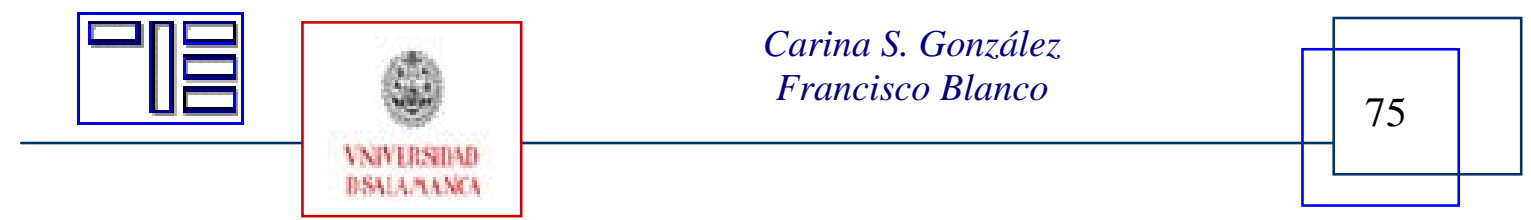


consecuencia, la complejidad técnica de estos juegos ha sido escasa, resultando en muchos casos limitados a tareas repetitivas y de escaso atractivo.

Por el contrario, algunos de los videojuegos comerciales han sido los número uno de los desarrollos multimedia, pero sólo recientemente, con una nueva generación de juegos comerciales, diseñados de manera que las comunidades en torno a ellos pueden agregarles nuevos contenidos y modificarlos, se abre la posibilidad de adaptarlos para usos diferentes de los puramente lúdicos, y entre ellos los educacionales.

En la siguiente sección veremos algunos ejemplos de usos educacionales de juegos 3D comerciales.

\section{EJEMPLOS DE USOS EDUCACIONALES DE JUEGOS 3D}

Como ejemplo de usos educacionales de juegos 3D comerciales, se sitúa en una posición destacada "Second Life" por su transcendencia para las comunidades virtuales de aprendizaje. Existen decenas de proyectos educacionales y una literatura académica incipiente relacionadas con el mismo. Recientemente, la compañía que publica y mantiene el juego, Linden Labs. ha creado incluso una zona especial llamada "Campus: Second Life” que reúne a Universidades, Bibliotecas, Museos y otras instituciones relacionadas con la enseñanza haciéndoles una oferta económica especial. Entre los sitios educacionales más relevantes encontramos por ejemplo a:

- Harvard Law School's Austin Hall

- El U.S. Centers for Disease Control and Prevention (CDC)

- Ohio University Second Campus

- Northern Illinois University

- VINEC - Virtual Neurological Education Centre

Cabe destacar como antecedente a nuestra propuesta, el proyecto Sloode. En este proyecto se busca integrar Moodle con Second Life, combinando las herramientas de aprendizaje de un LMS (Learning Mannagement System) sobre web con la riqueza e interactividad de un entorno gráfico en 3D que usa la tecnología sofisticada de los juegos. En nuestro caso, hemos integrado un motor de juego en 3D, llamado Neverwinter Nights, con la plataforma del elearning Moodle. Neverwinter Nights es un videojuego de rol en tercera persona en 3D basado en la tercera versión de las reglas del juego de rol Dragones y Mazmorras (Calabozos y Dragones) en el que se juega en escenarios, publicado y mantenido por la empresa Bioware Inc. Este videojuego presenta una serie de características que lo hacen muy interesante para este tipo de propósito y que analizaremos más adelante, que han hecho que también haya sido utilizado en una serie de proyectos educacionales experimentales. Un ejemplo es el proyecto Revolution, desarrollado por el MIT y la Univeridad de Wiscosin-Madison que ambienta el juego en la ciudad colonial de Williamsburg de 1775 y los hechos históricos que produjeron la revolución que condujo a la independencia de Estados Unidos, haciendo que los participantes entiendan mejor la historia de su país encarnando a diferentes tipos de habitantes de las colonias: abogados de clase alta, esclavos de las plantaciones, comerciantes..., cada uno

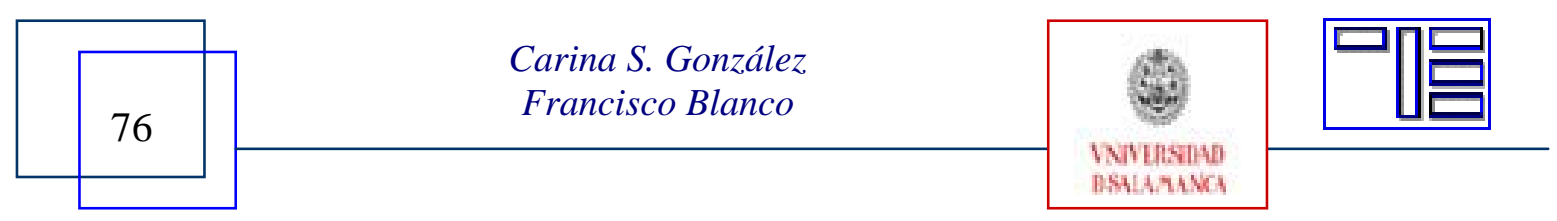


de ellos con unas motivaciones e intereses diferentes. Los estudiantes se ven así en la situación de tomar decisiones razonadas que concuerden con el papel que desempeñan, interaccionando con los personajes de la ciudad y con sus compañeros de juego. El entorno pone a los jugadores/alumnos en situaciones que les exigirán cooperar, debatir y competir.

Otro proyecto interesante es el "NWN Learning Environment" de West Nottinghamshire College y Peter Gorniak (MIT) recientemente premiado con el "Beacon Award for Innovation”. Dirigido a alumnos de secundaria ha tenido un notable éxito en mejorar los resultados de los alumnos en las llamadas "habilidades clave" (numéricas y comunicación). En él se crean "aventuras" a medida de los objetivos curriculares en estas materias en los que los jugadores/alumnos deben resolver problemas en contexto para seguir progresando en el juego.

Por otra parte, el NWN ScriptEase es un proyecto de la Universidad de Alberta (Canadá) que aborda la creación de una herramienta que facilite el uso de NWNScript para los docentes sin conocimientos de programación, de modo que puedan crear adaptaciones educativas con mayor facilidad. La idea aquí es que los profesores puedan elaborar "aventuras" de manera sencilla que se adapten a los objetivos del curriculum. Como ejemplo de uso de NWN para la educación superior podemos citar al proyecto de la Escuela de Periodismo y Comunicación de Masas de New Media Institute (EEUU). Las autoras del proyecto experimentan con la eficacia de los juegos para tareas educacionales en este marco poniendo a los jugadores/alumnos en el papel de periodistas que deben elaborar un artículo que informe sobre el descarrilamiento de un tren. Para ello deben hacer entrevistas, y hacer trabajo de investigación periodística. Es una especie de simulación de una situación real.

\section{EMOCIONES Y VIDEOJUEGOS}

Abordaremos el concepto de las emociones desde el un enfoque sociocultural (Rebollo y otros, 2008). Esta perspectiva científica de las emociones se sustenta en las siguientes consideraciones: a) los sentimientos no constituyen un proceso exclusivamente individual e interno, sino un proceso relacional, por tanto la emoción se construye socialmente; b) las emociones están mediadas por instrumentos y recursos culturales de naturaleza simbólica, provenientes de los contextos sociales; y c) los sentimientos suponen indicadores de la relación que establecemos con los contextos, por ello, actuamos en relación con los valores culturales aceptándolos o rechazándolos. Este enfoque nos permite centrar el análisis de las emociones en tres ejes principales: social, instrumental y mediada y por último, dependientes del contexto. Utilizamos este enfoque ya que se encuentra muy relacionado con el área de investigación de los factores humanos en la IPO. Los videojuegos son, poderosos generadores de emociones. Varios autores, se han centrado en analizar qué emociones pueden generarse, y de cómo modo surgen éstas (Frome, 2007). Es posible distinguir dos niveles en la vivencia de emociones:

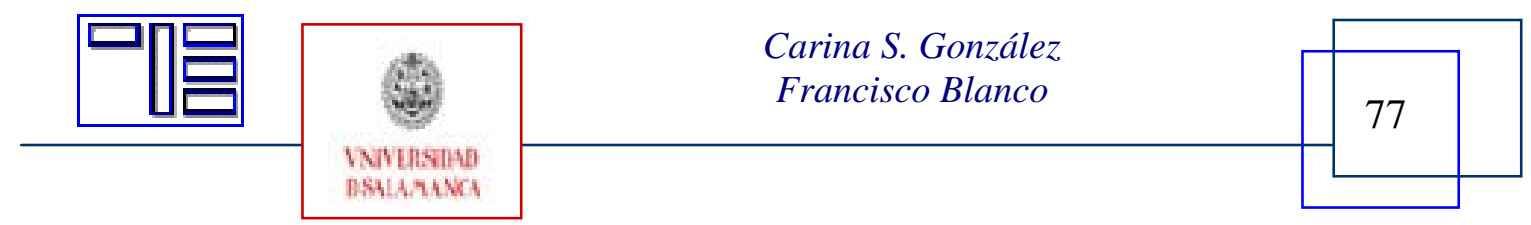


- El jugador como observador-participante: Se refiere a las emociones producidas por la interacción con las imágenes y el sonido del videojuego, por aquellos elementos que el participante no puede cambiar, y los mecanismos que las inducen son similares a los utilizados por las películas de cine. Por ejemplo, un jugador podría asombrarse al percibir la belleza de un escenario de juego.

- El jugador como actor participante: Se refieren a las emociones generadas por las propias acciones del jugador, o de las interacciones del jugador con otros. Por ejemplo, un jugador podría sentir alegría como resultado de haber conseguido superar una fase. En los videojuegos, a diferencia de otros formatos multimedia, y particularmente los videojuegos multijugador, se posibilitan estas emociones.

En el campo de los videojuegos en particular, varios autores han analizado como los videojuegos se presentan como elementos que favorecen la motivación por ser intrínsecamente satisfactorios (Ryan, 2006). Esta satisfacción provendría esencialmente del caudal de emociones generado al obtener logros, al disfrutar de libertad de acción y al interactuar con otros jugadores.

La propuesta lúdica desarrollada en este trabajo se encuentra dentro de la tipología de juegos de rol multijugador. En este tipo de juegos la ambientación general, la caracterización de los jugadores, y en general un clima de emoción y sorpresa, constituyen gran parte del atractivo. En el mismo, cada jugador adopta un personaje y distintos roles según criterios que se definen dentro del equipo en las distintas fases del juego. El equipo deberá superar una serie de desafíos y obtener una serie de conceptos claves y recompensas.

Los aspectos emocionales cobran gran importancia en los juegos de rol y más aún, si se tiene en cuenta que los videojuegos en primera/tercera persona tienen el potencial de inducir casi cualquier emoción posible en los jugadores. Esto puede lograrse haciendo que el usuario se identifique y se implique emocionalmente con lo que sucede en la pantalla. Con los juegos de rol en primera/tercera persona y la manipulación directa, se produce un fuerte sentimiento de inmersión (participación directa en un mundo de objetos vs. comunicación con intermediario), al producirse una identificación entre estudiante/jugador y el avatar que lo representa en el mundo virtual. Tal identificación hace que las interacciones sociales entre avatares se perciben como interacciones entre personas.

Nos preguntamos entonces, ¿cómo podemos despertar estas emociones con los videojuegos de rol multijugador? y ¿cómo podemos aprovechar estas emociones para propiciar el aprendizaje?. Para poder dar respuesta a estas preguntas, primero debemos concretar qué emociones son las que podemos analizar y para ello vamos a utilizar una taxonomía de emociones similar a la de Ekman (1999).

o Interés: El interés se puede conseguir básicamente con una historia coherente y la capacidad de inmersión en la misma. Los alumnos tienen que tener en

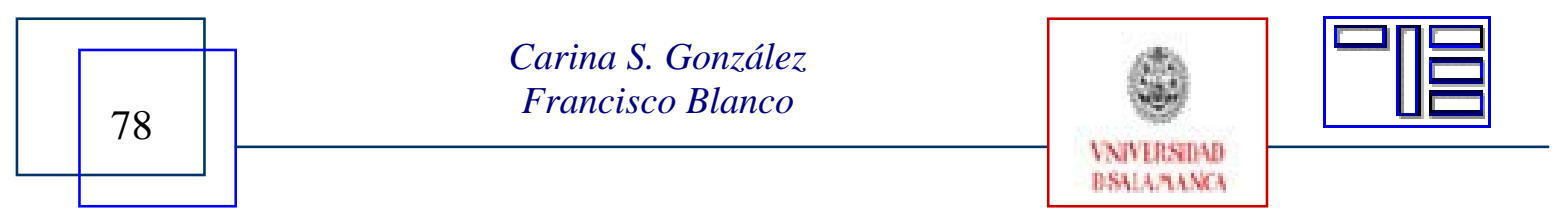


claro lo que tienen que hacer en cada momento y a donde tienen que llegar, pero no puede desvelarse la línea argumental concreta de la misión a realizar para mantener el interés.

o Humor: El humor lo logramos a través del absurdo o la ironía de las situaciones y mediante la caracterización e interpretación del rol de los personajes.

o Felicidad: La felicidad o satisfacción se consigue cuando alcanzan los objetivos individuales como mejorar el personaje o relacionados con la línea argumental al ayudar a un amigo o vencer un enemigo.

o Sorpresa: La sorpresa se consigue a través de reveses inesperados en la línea argumental o descubrimiento de líneas argumentales alternativas.

o Ansiedad: La ansiedad se produce cuando un alumno se ve aparentemente incapaz de conseguir los objetivos o se ve en una situación particularmente difícil. Esto deriva según el carácter del alumno en disgusto, tristeza, hostilidad e ira, o por el contrario, estimula la creatividad para resolver el problema e incrementa la percepción del desafío y el esfuerzo para conseguirlo.

o Amor: Generalmente el jugador “ama” al personaje con el cual se identifica, por que es fruto de su esfuerzo y del tiempo dedicado, aunque también puede darse el caso de amar determinadas situaciones (i.e. vencer a determinado enemigo, ser capaz de hacer algo que el resto no puede) o determinados objetos (i.e. pociones, espadas, etc.). Cuando un alumno se siente capaz de hacer cosas por el grupo y sentirse útil en el grupo, se fomenta amor al personaje y felicidad para el jugador.

o Hostilidad: La hostilidad es un sentimiento negativo hacia otros producido por la percepción de que pueden hacerle daño. Esta emoción puede aparecer en el juego cuando una persona percibe que otra puede bloquearle el logro hacia un objetivo o actividad.

o Tristeza: La tristeza es una emoción relacionada con eventos no placenteros que le han ocurrido a una persona. Generalmente, está relacionada con los motivos que llevaron a no haber alcanzado los objetivos y no con la pérdida en sí misma. Suele provocar una disminución de la atención hacia el ambiente externo y una disminución de las conductas de gratificación.

o Repulsión: La repulsión es una emoción implicada en conductas de huida o rechazo. Sirve para alejarnos de situaciones de peligro o que nos pueden causar algún perjuicio. Un videojuego puede apoyarse en esta reacción emocional para atraer al público, al igual que las películas de terror, provocando situaciones de alta tensión emocional.

o Ira: La ira es la emoción que surge cuando se percibe que algo está bloqueando el camino hacia el logro de los objetivos, diferenciándose de la

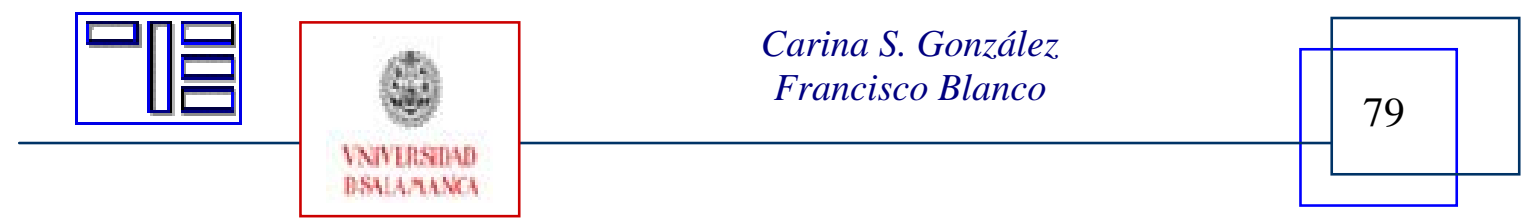


hostilidad por que en la misma se percibe que hay "algo" o "alguien" que puede bloquearlo. Esta emoción es frecuente en los videojuegos, sobre todo en los altamente competitivos.

Así mismo, podemos afirmar que las emociones son una parte importante del motor de aprendizaje, siendo un medio de reforzar o extinguir conductas. De estas emociones, por su influencia en el aprendizaje podemos destacar la motivación que producen, ya que sin motivación los estudiantes tienden a experimentar apatía, inactividad, pasividad y se dificulta el aprendizaje (Sacristán Díaz, 2003). De ahí el interés de fomentar la motivación, utilizando diferentes estrategias que influyan en dichos factores. Las motivaciones para el aprendizaje se derivan de las motivaciones en el juego. Básicamente podemos identificar cuatro motivaciones principales en el juego a saber: a) la colaboración con el grupo, b) la resolución de problemas, c) completar el juego y d) la mejora del propio personaje. El creador de la experiencia tiene que tener en cuenta estas motivaciones para ubicar las actividades en la línea argumental correctamente de forma que estén relacionadas con los objetivos del jugador.

Por otra parte, el uso controlado y racional de los videojuegos puede ser un campo de prueba social en donde se ensayan diferentes roles, ya que la persona se identifica e implica con los personajes allí presentados produciéndose un proceso inmersivo. De esta manera, la experiencia en un videojuego se transforma en una experiencia emocional tan natural como la que se produce en el mundo real. Las relaciones sociales dentro del juego pueden darse entre iguales en la cooperación intragrupo y en la cooperación extragrupo. Tanto en las relaciones inter o intra grupo pueden darse actitudes de colaboración, de competencia o de abierta hostilidad. Evidentemente, las relaciones dentro de un mismo grupo han de ser de colaboración para favorecer a la efectividad del mismo, aunque también consideramos recomendable la competencia entre los grupos ya que incrementa la motivación en el logro de objetivos.

\section{6.- PROCESO DE DISEÑO DE UNA INTERFAZ EMOCIONAL LÚDICO- EDUCATIVA}

El objetivo de este trabajo es analizar la manera en que los usuarios interactúan para lograr los desafíos que se les plantean dentro del juego, valorar los factores emocionales que han intervenido en el proceso y como éstas influyen en la motivación para aprender. Para ello, el primer paso es crear una interfaz de usuario que responda a las necesidades del usuario y permita modelar las interacciones que influyen en los aspectos emocionales y cognitivos. Para diseñar e implementar esta interfaz hemos seguido una metodología general de diseño de sistemas interactivos proveniente del área de la Interacción Persona-Ordenador (IPO), en concreto la metodología de Diseño Centrado en el Usuario (DCU), que resulta adecuada para abordar este problema. Esta metodología de diseño permite minimizar la sobrecarga cognitiva y perceptiva del usuario de una aplicación. Utiliza un método de diseño iterativo con prototipado, cuyo esqueleto es el ciclo "análisis-diseño-implementación-evaluación" que se repite varias veces con vistas a ir

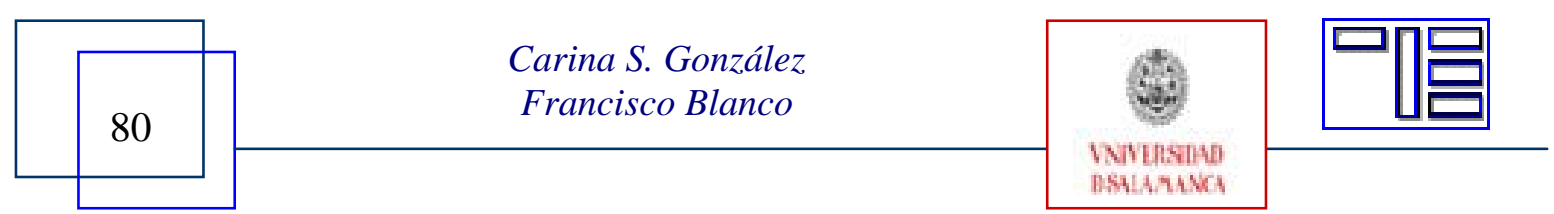


mejorando progresivamente el sistema. En cada repetición del ciclo, en la etapa de evaluación del prototipo, el sistema es confrontado con usuarios reales. En la fase de análisis se ha utilizado el enfoque de escenarios de Leite (2000) que incluye el uso de lenguaje natural para la elicitación y su construcción (Liu y Yu, 2001).

El proceso continuó con la fase de diseño iterativo y evaluación del prototipo, en dónde se llevaron a cabo cinco pruebas piloto utilizando la interfaz diseñada, para de esta forma evaluar el prototipo en un entorno y situación de aprendizaje real.

Respecto a los métodos de evaluación, hemos utilizado los métodos por indagación: observación de campo, logging y cuestionarios.

\section{1.- Fase de análisis: definición de perfiles de usuario y roles en el contexto del videojuego}

En esta fase de análisis de requisitos, hemos analizado los escenarios de nuestro juego, y en los mismos, hemos definido los objetivos, las tareas, el contexto de uso, los perfiles de usuarios y los casos de uso (González y Blanco, 2008). Nos centraremos en esta sección en el análisis de los perfiles de usuario y sus roles en el contexto del videojuego. A efectos de la experiencia del usuario dentro del juego, hemos distinguido dos niveles de rol: uno relacionado con el propio juego, y otro relacionado con su papel en la actividad de aprendizaje.

En primer lugar, cada participante asume un rol en relación al propio juego. Así por ejemplo, un participante puede ser un "guerrero", o un "pícaro", y esto afecta a qué habilidades tienen sus personajes dentro del juego, y cómo se desenvuelven en el mismo. Por ejemplo, los "guerreros" ejercerán su papel de protectores y defensores del grupo, mientras los pícaros se ocupan de ir explorando el camino, abriendo las cerraduras que obstruyen el paso del grupo y quitando las trampas del escenario de juego. Los profesores también toman parte en lo puramente lúdico en su aspecto de "Dungeon Master”, poniendo o quitando obstáculos en el camino de los jugadores, interaccionando con ellos a través de avatares, etc. Pero además, cada participante desarrolla un rol relacionado con su papel dentro de la actividad de aprendizaje. De este modo, en nuestra actividad tendremos:

- Alumnos: Toman parte en la actividad grupal debatiendo y aportando sus conocimientos para llegar a las respuestas correctas.

- Portavoz: habla por el equipo cuando hay que dar una respuesta común a alguna cuestión planteada y coordina las decisiones a tomar.

- Profesor: Guía la actividad de aprendizaje y evalúa a los alumnos.

Estos dos niveles de rol se relacionan entre sí, por ejemplo, un profesor puede encarnar el avatar de un personaje que da una pista sobre un contenido de la asignatura necesario para completar un puzzle.

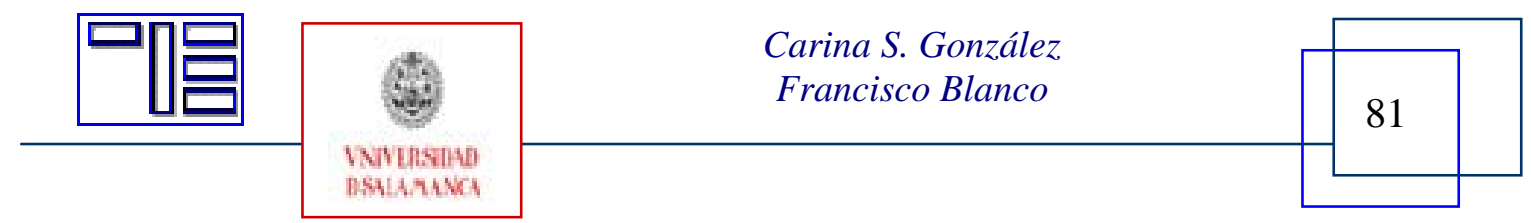


Revista Electrónica Teoría de la Educación.

Educación y Cultura en la Sociedad de la Información.

http://www.usal.es/teoriaeducacion

Vol. 9. No3. Noviembre 2008

\section{2.- Fase de Diseño: actividades diseñadas}

La forma de lograr los objetivos planteados en la investigación utilizando el videojuego, se realizó mediante el diseño de distintas actividades, tal como se indica a continuación:

o Actividad 1. Familiarización con el entorno: Para poder comenzar con las actividades de aprendizaje planteadas en el juego, los estudiantes debían primero aprender a "jugar" en el entorno. Para ello, se les habilitó un tutorial del juego, donde habían distintos personajes que iban guiando la acción, contándoles como desenvolverse dentro del entorno y con los objetos del mismo.

o Actividad 2. Rol y Caracterización: Cada estudiante debía crear su propio personaje, asignándole su personalidad, apariencia física, vestuario y poderes. Asimismo, tenían que asignarle un nombre. Este nombre de personaje debía ser relacionado con el nombre del alumno correspondiente, de forma que el profesor y sus compañeros pudieran identificarlo en el entorno. Luego dentro del entorno, debían recorrer un laberinto en donde se presentaban y reconocían. Esta sesión contenía además elementos lúdicos de acción, como monstruos, demonios y otros personajes con los cuales debían interactuar. Además en esta fase debían adquirir todos los complementos para afrontar los desafíos que se plantean en el laberinto de conceptos.

o Actividad 3. Agrupación: Por medio de una supuesta teletransportación a una biblioteca, los alumnos debían agruparse y sobre todo, aprender a conversar. Esta biblioteca tenía distintas salas con sillas y sofás para sentarse a charlar y también habían distribuidos distintos cofres con conceptos y capas de colores: azul, verde, rojo y amarillo. Cada color identificaba a un grupo, y los alumnos tenían que ponerse la capa de un determinado color. De esta manera se formaron 4 grupos distintos con 5 miembros cada uno. Los grupos debían recoger 5 conceptos para completar un texto sobre un tema donde faltaban palabras claves. Los temas eran: Accesibilidad, Usabilidad, Diseño Centrado en el Usuario y Factores Humanos. La validación la tenían que realizar entre los grupos: el grupo azul validaba la solución del rojo y viceversa, y de la misma manera lo hacía el grupo verde con el grupo amarillo. En esta fase del juego los miembros del equipo debían designar un máster que será el responsable de la interlocución con los demás grupos y con el profesor.

o Actividad 4. Laberinto de conceptos sobre IPO: En esta actividad debían buscar y recolectar conceptos de distintos temas. Los temas a los cuales pertenecían los conceptos eran desconocidos a priori. Al finalizar el laberinto deben seleccionar un tema y tener como mínimo 4 conceptos del mismo, para poder pasar a la siguiente fase. Si no lo tienen, deben volver al laberinto a buscar más conceptos y/ó negociar con otros grupos los conceptos que les falten conseguir. Los roles que cumplen en esta fase del juego los miembros del equipo

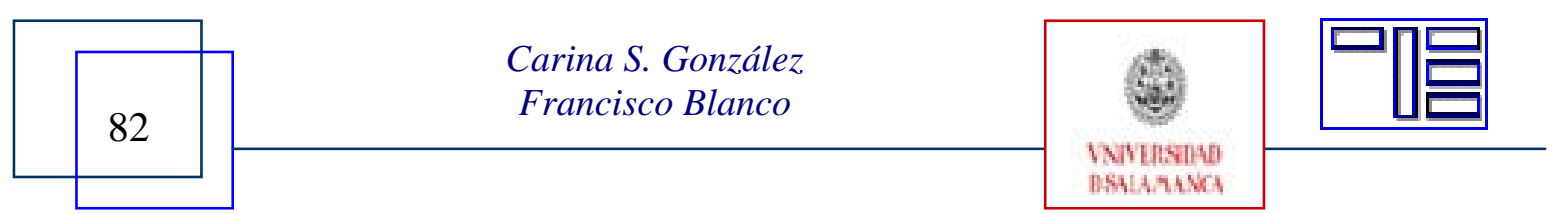




\begin{tabular}{|c|c|c|}
\hline 밈ㅁㅁ & $\begin{array}{l}\text { Revista Electrónic } \\
\text { Educación y Cultura en }\end{array}$ & $\begin{array}{l}\text { Educación. } \\
\text { la Información. }\end{array}$ \\
\hline & http://www.usal.es/teoriaeducacion & Vol. 9. Nº3. Noviembre 2008 \\
\hline
\end{tabular}

son: recolectores (buscan y recogen los distintos objetos, pueden además hablar con otros recolectores para obtener objetos), guardianes (protegen a los demás miembros en las misiones y custodian los tesoros obtenidos) y máster (responsable de la interlocución con los demás grupos y el profesor)

o Actividad 5. Tiendas de conceptos (Negociación): En esta fase los equipos deberán obtener 6 conceptos extra, de los cuáles 3 conceptos deben ser negociados con otros equipos y los restantes 3 con el profesor. Cada equipo se instaló en una tienda y fue visitando las demás tiendas en búsqueda de los conceptos que le faltaban de su tema (elegido en la fase anterior). El profesor además tenía una tienda propia, con conceptos "exclusivos", los cuales tenían un precio más alto, y se debían superar las preguntas asociadas a los mismos y planteadas por el profesor. Aunque el interlocutor con el profesor sea el máster, éste en todo momento puede consultar con sus compañeros de equipo las respuestas a las preguntas planteadas por el profesor.

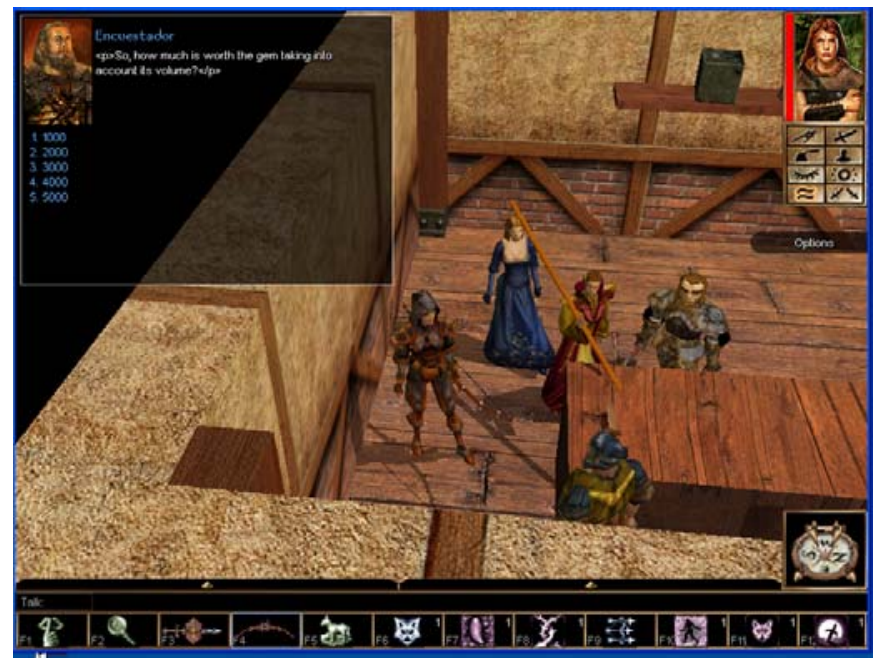

Figura 1. Prototipo realizado en NWN

Una vez superadas las distintas actividades propuestas en el juego, que incluyen búsqueda, descubrimiento, negociación, competitividad y cooperación, obtendrán 10 conceptos clave con los que el equipo puede construir un mapa conceptual colaborativo de un determinado tema relacionado con el área de la IPO. Finalmente, los mapas debían ser integrados en un mapa conceptual global de la asignatura dentro del aula virtual.

\section{3.- Fase de implementación: prototipo implementado y evaluación}

Para implementar el prototipo se ha utilizado el motor Neverwinter Nights (NWN). NWN es un videojuego de rol en tercera persona en 3D basado en la tercera versión de las reglas del juego de rol Dragones y Mazmorras (Calabozos y Dragones) en el que se juega en escenarios. Publicado y mantenido por la empresa Bioware Inc. NWN es idó-

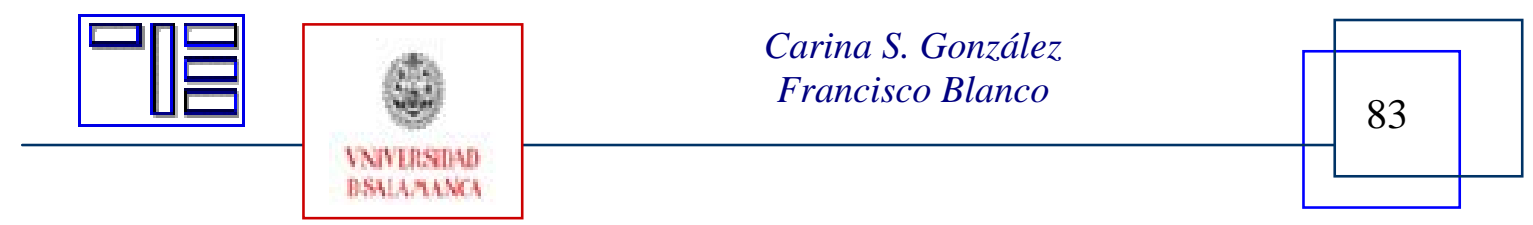


neo para este tipo de actividades, ya que tiene una serie de características poco frecuentes en los juegos de rol:

1. Fue diseñado para ser modificado, permitiendo crear de forma sencilla y flexible una gran variedad de escenarios de juego (y en nuestro caso, de aprendizaje).

2. Es un juego multijugador que incluye la posibilidad de que los usuarios tengan diferentes privilegios de acceso, lo que posibilita entre otras cosas, que los profesores tengan cierta capacidad para modificar el escenario mientras éste tiene lugar o que puedan encarnar distintos avatares con los que interaccionar con los jugadores. Así mismo, permite a los investigadores observar la acción que tiene lugar en el juego por medio de avatares indetectables y que por tanto no interfieren en el desarrollo de las acciones de los alumnos.

3. Permite crear experiencias con entornos controlados, a diferencia de lo que ocurre en los juegos multijugador masivos, donde es posible impedir la interferencia de personas o elementos del juego que no tienen que ver con la propia actividad.

También hemos usado el sistema de gestión de cursos ó LMS llamado Moodle. Moodle destaca por su madurez y su amplia comunidad de usuarios, por dar soporte a distintos estilos de aprendizaje y su enfoque al trabajo colaborativo, y porque es una plataforma que se basa en código abierto que utilizando tecnologías estándar y una arquitectura modular que permite añadirle nuevas características de un modo relativamente fácil.

\subsection{1.- Instrumentos y resultados de la evaluación}

La evaluación del prototipo fué llevada a cabo en distintas sesiones presenciales, en horario lectivo, en un aula de informática con 25 alumnos del 3er curso de la asignatura de Sistemas de Interacción Hombre-Máquina de la Escuela Técnica Superior de Ingeniería Informática de la Universidad de La Laguna. Los alumnos no estaban obligados a ir, ya que esta práctica no puntuaba en la nota final.

En las distintas sesiones del juego cada estudiante fue recogiendo en su propio blog dentro de Moodle, un diario de actividad, comentando sus progresos, dificultades y percepciones, así como respondiendo a las preguntas que el profesor planteó durante cada sesión.

Otros instrumentos utilizados en el proceso de observación fueron: registros de las interacciones, conversaciones entre participantes, rutas seguidas, grabación en vídeo de las sesiones y diario del profesor.

En el proceso de observación realizado en las distintas sesiones podemos realizar las siguientes consideraciones:

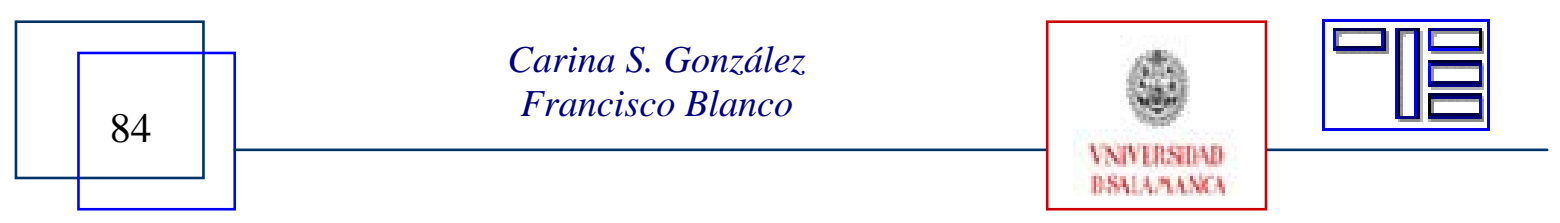




\begin{tabular}{|c|c|c|}
\hline \multirow[t]{2}{*}{ घ" } & \multicolumn{2}{|c|}{$\begin{array}{l}\text { Revista Electrónica Teoría de la Educación. } \\
\text { Educación y Cultura en la Sociedad de la Información. }\end{array}$} \\
\hline & http://www.usal.es/teoriaeducacion & Vol. 9. $N^{\circ}$ 3. Noviembre 2008 \\
\hline
\end{tabular}

- El primer día, notamos que la interfaz del juego resulta para los alumnos más difícil de lo que habíamos supuesto, tardando algún tiempo en familiarizarse con elementos tales como el inventario de los personajes y las herramientas de comunicación "verbal" y gestuales del juego. Los alumnos no son capaces de actuar de forma coordinada ni de comunicarse dentro del juego de forma efectiva. Por ejemplo, tratan de enfrentarse a los monstruos del laberinto individualmente, lo que hace que sean derrotados. El carácter lúdico de la actividad conduce a algunos alumnos a no tomársela del todo en serio, cosa que se manifiesta en el uso de nombres de personaje "graciosos" y actitud ligeramente disruptiva. No obstante, reconducen su comportamiento en poco tiempo y sin que apenas sea necesario ejercer presión.

- El segundo día introdujimos un cambio en las actividades previstas, para corregir el hecho de que en la primera sesión la comunicación entre los jugadores dentro del juego había muy escasa y de poca calidad. En este segundo día se plantea a los jugadores una actividad accesoria o complementaria a la principal, en la que se desprovee al juego casi totalmente de su componente de "acción" y nos centramos en el de la comunicación. Los jugadores, además, deben organizarse en equipos, exhibiendo sus personajes un claro distintivo de color (una capa), lo que ayuda a saber perfectamente quien es quien en cada momento. La mayor parte del tiempo, cada equipo debe actuar colaborativamente y comunicarse. Durante esta sesión los alumnos aprenden a comunicarse dentro del juego. La idea de distinguir claramente a los miembros de los equipos visualmente resulta de extraordinaria utilidad para los propios alumnos. A pesar del éxito comunicativo, los alumnos no consiguen terminar la actividad, cosa que atribuimos a que nos excedimos en la dificultad de la misma y que la sesión de juego fue demasiado breve.

- Durante el resto de sesiones, la actividad se lleva a cabo tal como se había sido programada. La mayoría de los alumnos dominan razonablemente bien el interfaz del juego y son capaces de actuar coordinadamente. Se reúnen por equipos, si bien en algunos equipos se observa que se dividen a su vez en grupos de 2 o tres alumnos. Se establece una cierta competencia entre equipos. Todos los equipos acaban finalizando la primera parte de la actividad, pero sólo da tiempo a que uno finalice con éxito la segunda parte (equipo ganador).

Con el fin de evaluar el componente afectivo-motivacional del prototipo diseñado, al final de la actividad se realizó un cuestionario a los alumnos, permitiéndoles mostrar su grado de acuerdo o desacuerdo en una escala de 1 a 5 con distintas preguntas relacionadas a la actividad realizada, a las emociones y a la motivación despertada durante las sesiones de trabajo. Los resultados obtenidos referentes a estas cuestiones fueron los siguientes:

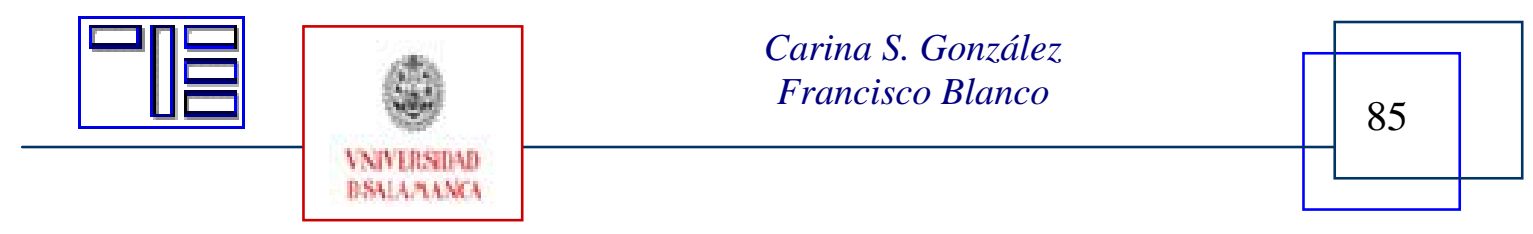


Revista Electrónica Teoría de la Educación.

Educación y Cultura en la Sociedad de la Información.

http://www.usal.es/teoriaeducacion

Vol. 9. No3. Noviembre 2008

a) Cuestiones generales sobre la actividad: Los alumnos consideran que la actividad es fácil, aunque un porcentaje representativo afirma que el tiempo destinado a la actividad ha sido insuficiente. Es destacable que cerca de un 30\% del alumnado manifiesta que los objetivos de la actividad no estaban claros. Interpretamos que el hecho de incluir un videojuego en la asignatura constituye una disrupción clara en la dinámica de clases presenciales y prácticas a la que los alumnos destinan la mayor parte de su tiempo presencial.

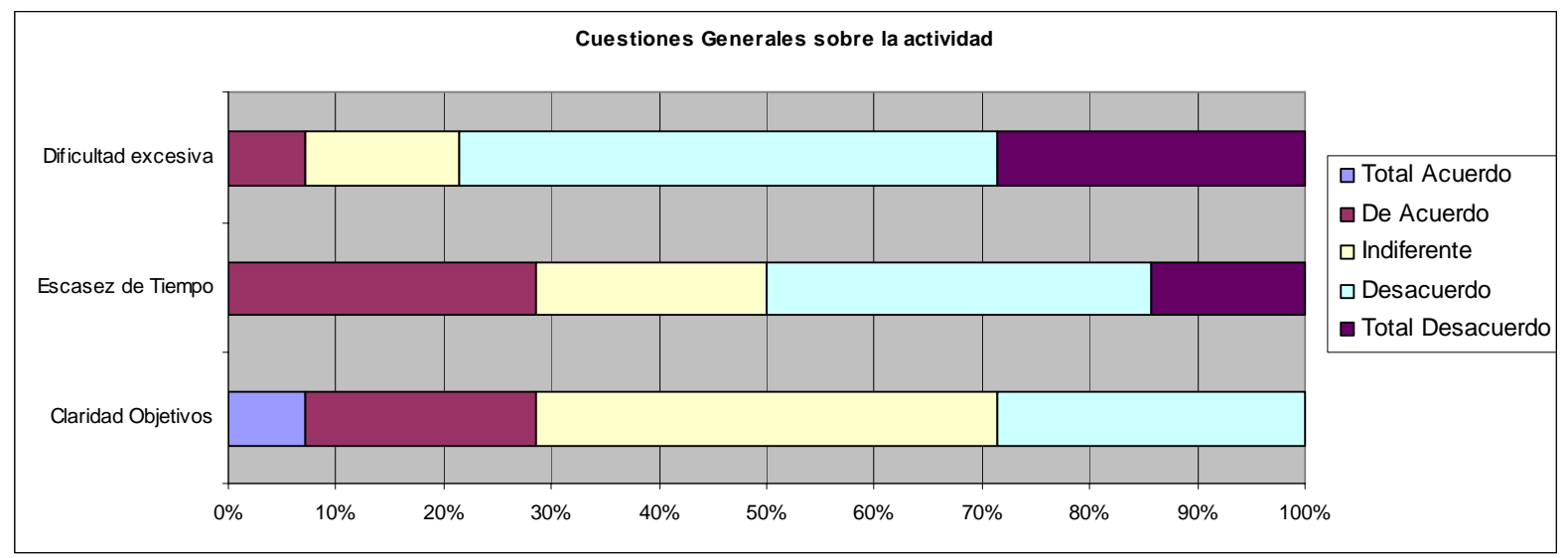

Figura 2. Cuestiones generales sobre la actividad.

b) Percepción de emociones: Esta categoría corresponde a una batería de preguntas relacionadas con las emociones sentidas durante el desarrollo de la actividad. A través de estas preguntas, constatamos que los alumnos han sentido un interés considerable por la actividad (78,6\% de acuerdo o muy de acuerdo) y que este se ha mantenido durante el desarrollo de la misma (64,3 \% de acuerdo o muy de acuerdo). Así mismo, la mayor parte de los alumnos manifiestan claramente que la actividad les fue divertida (humor, $85,7 \%$ ) y satisfactoria (felicidad, 71,4\%). Los sentimientos menos frecuentes fueron los de hostilidad, ya sea hacia sus compañeros de equipo o sus rivales. No obstante, confiesan haberse sentido ocasionalmente frustrados e incapaces de superar ciertos obstáculos.

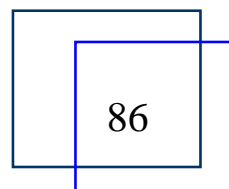

Carina S. González Francisco Blanco
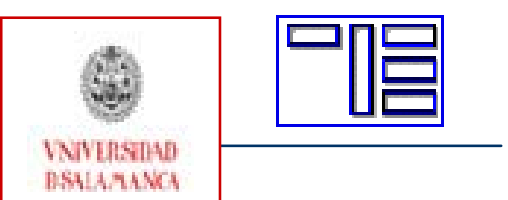


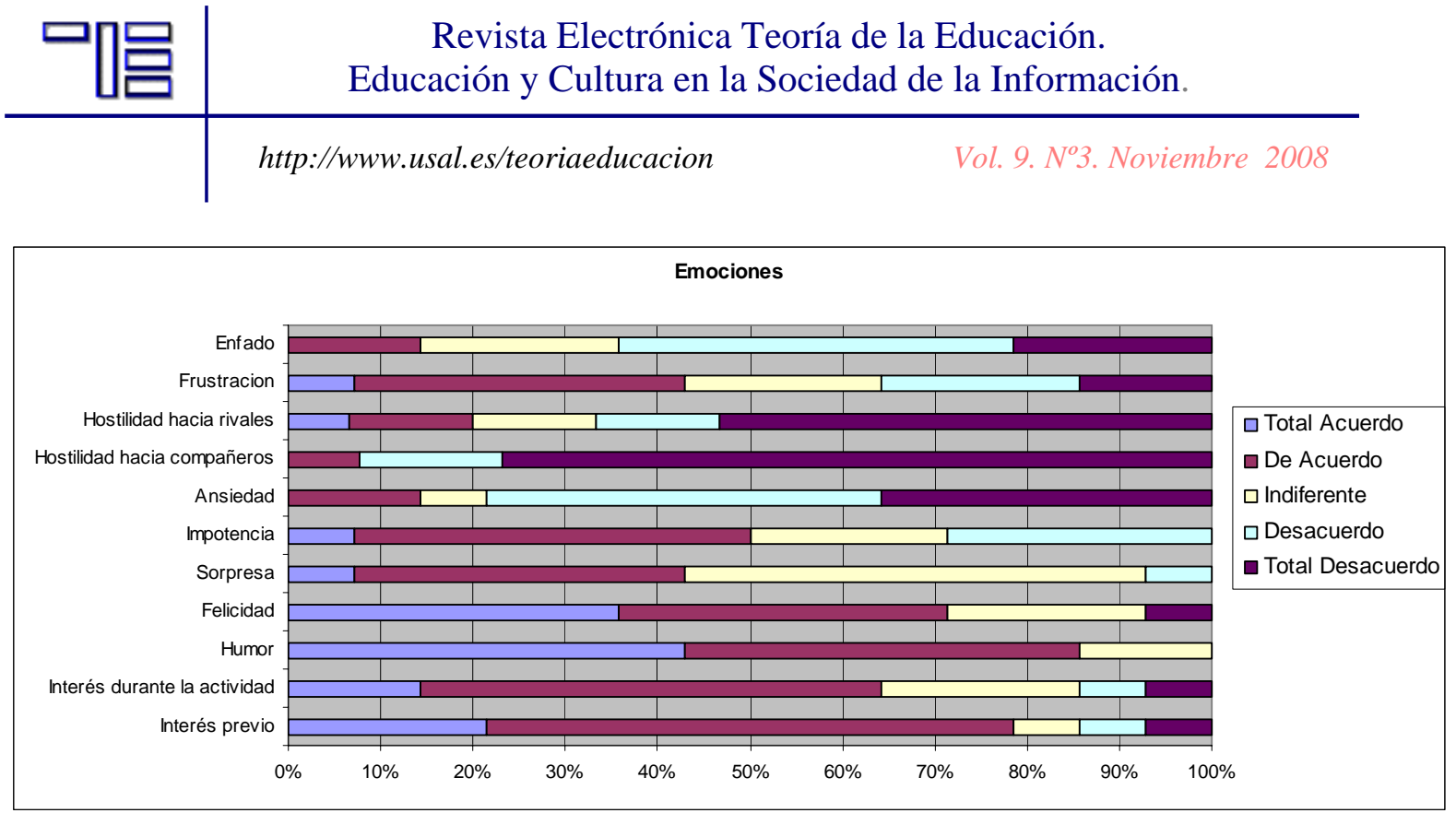

Figura 3. Emociones detectadas en el desarrollo de la actividad.

c) Motivación: preguntamos a los alumnos si esta actividad ha mejorado la motivación por la asignatura y si les ha resultado útil, obteniendo resultados muy prometedores. El $79 \%$ del alumnado ha respondido que esta actividad ha incrementado su motivación por la asignatura y el 71\% considera que esta actividad les ha resultado útil.

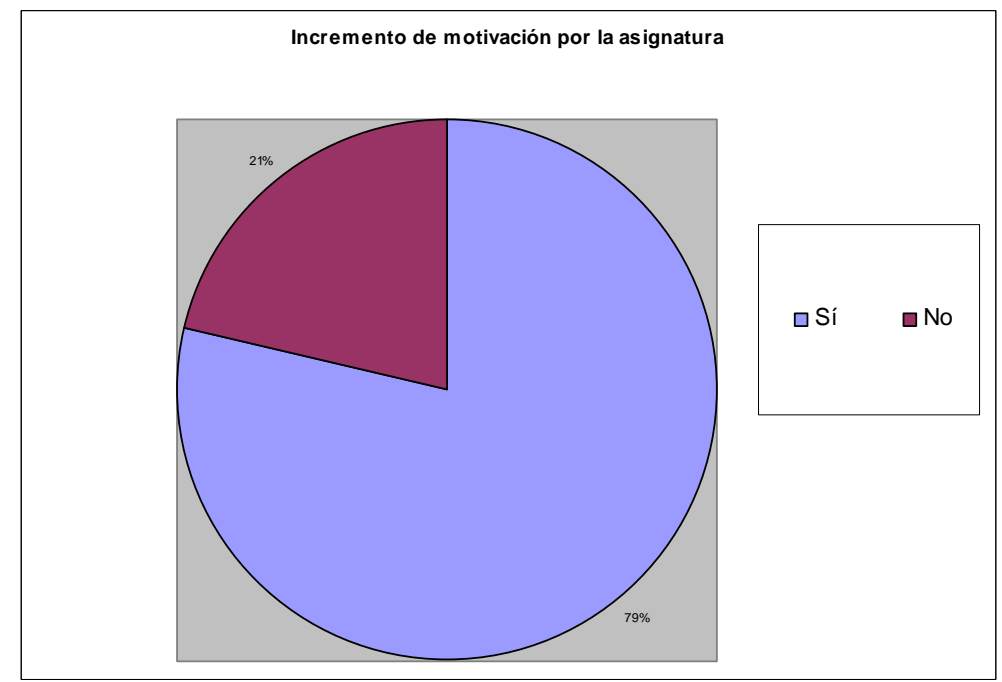

Figura 4. Porcentaje de incremento de la motivación por la asignatura

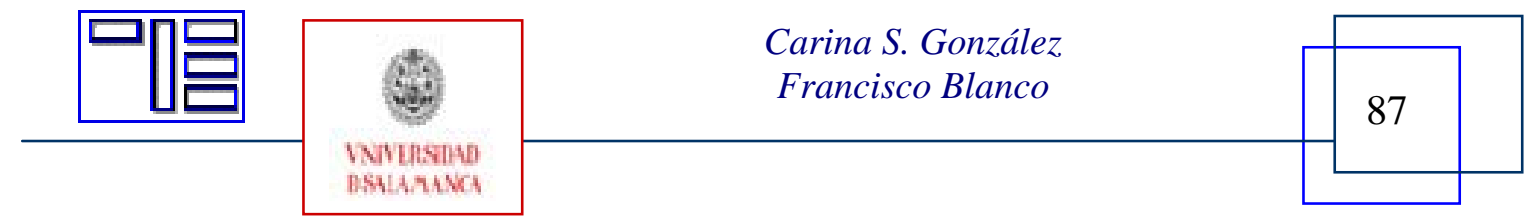




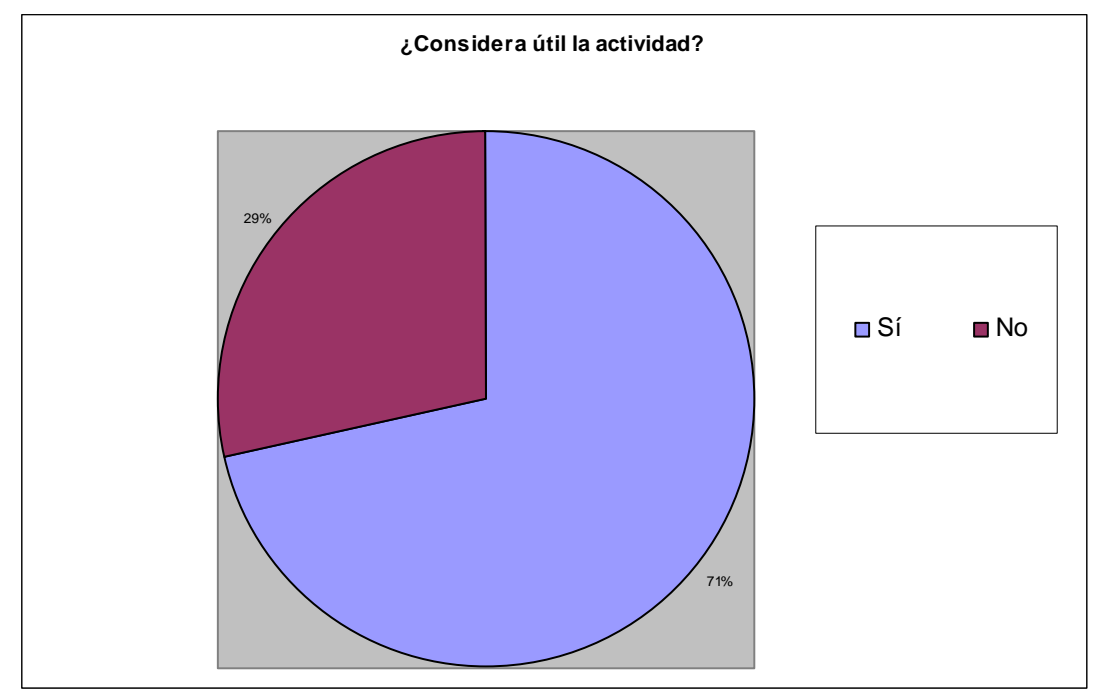

Figura 5. Grado de utilidad de la actividad con el videojuego para la asignatura.

Además de estas categorías de preguntas, se han analizado otras correspondientes a la usabilidad e interacción con la interfaz y a la comunicación realizada en el entorno 3D. Por otra parte, se realizaron preguntas en abierto para analizar un análisis cualitativo de por qué se producían las emociones y por qué consideraban que incrementaba o no la motivación hacia la asignatura y sobre la utilidad de esta actividad. Algunas características de la actividad reveladas en las respuestas en abierto fueron positivas (divertida, diferente, útil y una nueva forma de interaccionar con los compañeros y profesores, etc.) y negativas (no cuenta para nota, implica sobrecarga de trabajo, poco clara, etc.). De la misma forma, en las respuestas hacia la utilidad de la actividad, tenemos apreciaciones positivas (percepción de los videojuegos como un modo de comunicación, amplía la visión de la interacción-hombre máquina, aprendizaje de conceptos, estímulo de la curiosidad, etc.) y negativas (habría que haber incluido más contenidos de la asignatura, pérdida de clases magistrales, no ha dado tiempo de nada, etc.).

\section{6.- CONCLUSIONES}

En este artículo se ha presentado el diseño e implementación de un prototipo utilizando la metodología DCU, que integra parcialmente la plataforma Moodle con el juego Neverwinter Nights (NWN) y su experimentación con alumnos universitarios de la asignatura de Sistemas de Interacción Hombre-Máquina.

La visión de que los recursos tecnológicos por sí mismos incrementan el aprendizaje es ingenua, ya que los mismos pueden tanto incrementar como influir negativamente en la adquisición de conocimientos. Por ello, se debe investigar para comprender cómo interactúan los usuarios con estos recursos y entre ellos mismos y qué variables están implicadas en este proceso.

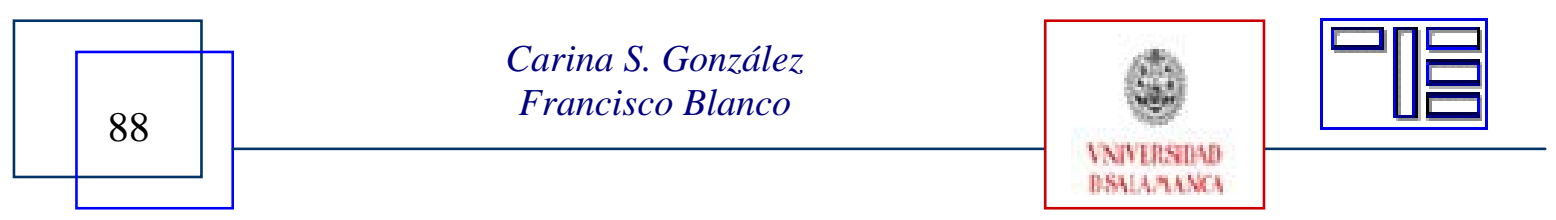


Por otra parte, las emociones pueden influir positiva o negativamente en el aprendizaje y sobre todo en la motivación para el aprendizaje. Lograr que un alumno se sienta o no motivado a aprender "algo" es una de las claves del aprendizaje autónomo. Entendemos que no sólo la motivación producida por los videojuegos puede ser beneficiosa en una actividad educativa con videojuegos. La ligera frustración que típicamente producen los videojuegos unidos a los factores intrínsecamente satisfactorios que incluyen éstos, puede ayudar a que los alumnos-jugadores sean más persistentes a la hora de ejecutar las tareas de aprendizaje y que se centren más en ellas. La sorpresa o intriga generada por una trama bien construida o la hostilidad por un villano también pueden hacer que los estudiantes perseveren en las actividades de aprendizaje planteadas.

A la luz de los resultados de la información proporcionada por los alumnos y nuestras propias observaciones entendemos que el hecho de que una actividad sea lúdica parece implicar para algunos participantes que no puede ser una actividad de aprendizaje, especialmente en la enseñanza para adultos. Las causas de este hecho habría que buscarlas en el fuerte dominio y profundo arraigo de las clases magistrales como único formato presencial en nuestros sistemas de enseñanza.

\section{7.- BIBLIOGRAFÍA}

BARBERÁ, E. (2004). La enseñanza a distancia y los procesos autónomos de aprendizaje. LatinEduca 2004.com. Mendoza (Argentina). Fecha: Abril 2004.

BARROS BLANCO, B. (1999) Tesis Doctoral. Aprendizaje colaborativo en enseñanza a distancia. Entorno genérico para configurar, realizar y analizar actividades en grupo.

BARSALOU, L.W. (1999). Perceptual symbol systems. Behavioral and Brain Sciences, 22, 577-609.

BEREITER, C., \& SCARDMALIA, M. (1989). Intentional learning as a goal of instruction. In L. B. RESNICK (Ed.), Knowing, learning, and instruction: Essays in honor of Robert Glaser (pp. 361-392). Hillsdale, NJ: Erlbaum.

BROWN, J. S., COLLINS, A., \& DUGUID, P. (1989). Situated cognition and the culture of learning. Educational Researcher, 18, 32-42.

BURGOS D., MORENO-GER, P. SIERRA, J.L., FERNÁNDEZ B. (2007). Authoring Game-Based Adaptive Units of Learning with IMS Learning Design and < eAdventure>. http://hdl.handle.net/1820/944

CALVO, A. (2000): “Videojuegos y jóvenes”. Cuadernos de Pedagogía , n 291, pp. 5962

CARRETERO, M. (2004): “Psicología cognitiva y educación”. Posgrado en Constructivismo y Educación. Buenos Aires, FLACSO Argentina y UAM.

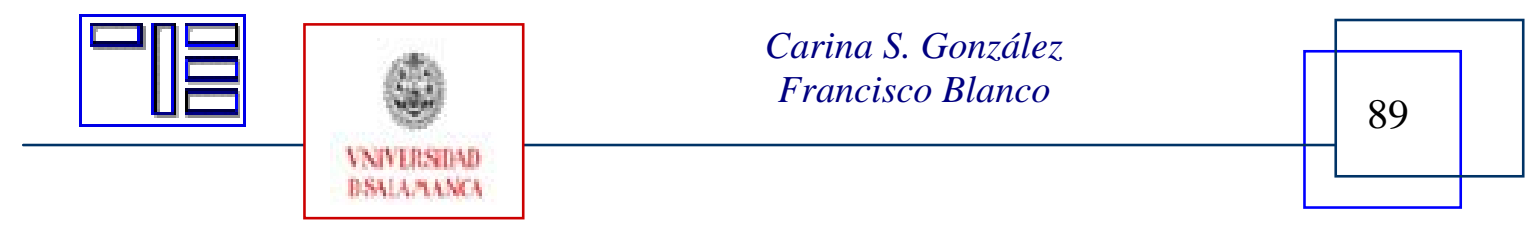


DE VICENTE, A. (2003): Towards Tutoring Systems That Detect Students' Motivation: An Investigation. Institute for Communicating and Collaborative Systems School of Informatics University of Edinburgh 2003.

DEL SOLDATO, T., \& DU BOULAY, B. (1996): Implementation of motivational tactics in tutoring systems. Journal of Artificial Intelligence in Education, 6(4), 337-378.

EKMAN, P. (1999). Basic Emotions. In T. Dalgleish and M. Power (Eds.). Handbook of Cognition and Emotion. Sussex, U.K.: John Wiley \& Sons, Ltd., 1999.

ELLIOTT, C. D. (1992). The affective reasoner: a process model of emotions in a multiagent system. Technical Report 32, Northwestern University. The Institute for the Learning Sciences.

ESTALLO, J.A.(1995), Los videojuegos. Juicios y prejuicios , Barcelona: Planeta

ETXEBERRIA, F. (1999): “Videojuegos y educación”, en Etxeberria, F. (Coord): La Educación en Telépolis . Editorial Ibaeta. Donostia.

FOREMAN, J. (2004) Game-Based Learning: How to Delight and Instruct in the 21st Century. EDUCAUSE Review.

FOREMAN, J. (2004). Game-Based Learning: How to Delight and Instruct in the 21st Century. EDUCAUSE Review

FROME, J. (2007). Eight ways videogames generate emotion. Situated Play, Proceedings of DiGRA Conference 2007.

GEE, J.P. (2003) What Video Games have to Teach us about Leaning and Literacy Pargrave MacMillan

GLENBERG, A. M.; ROBERTSON, D. A. (1999). Indexical understanding of instructions. Discourse Processes, Vol 28(1), 1999. pp. 1-26.

GONZÁLEZ TARDÓN, C. (2006): Emociones y Videojuegos, Actas del III Congreso del Observatorio de la Cibersociedad.

GONZALEZ, C., BLANCO, F. (2008). Integrating an educational 3D game in Moodle. In Journal of Simulation and Gaming. SAGE Publications. Volume 39 issue 3.

GROS, B. (2000), La dimensión socioeducativa de los videojuegos , Edutec. Revista Electrónica de Tecnología Educativa , $\mathrm{n}^{\circ} 12$

ISSROFF, K., \& DEL SOLDATO, T. (1996). Incorporating motivation into computersupported collaborative learning. In Proceedings of European conference on artificial intelligence in education. Ficha Tecnica, Lisbon.

JONNES, A \& ISSROF K. (2005). Learning technologies: affective and social issues in computer-supported collaborative learning. Computers \& Education. Volumen 44. 395-408. 2005.

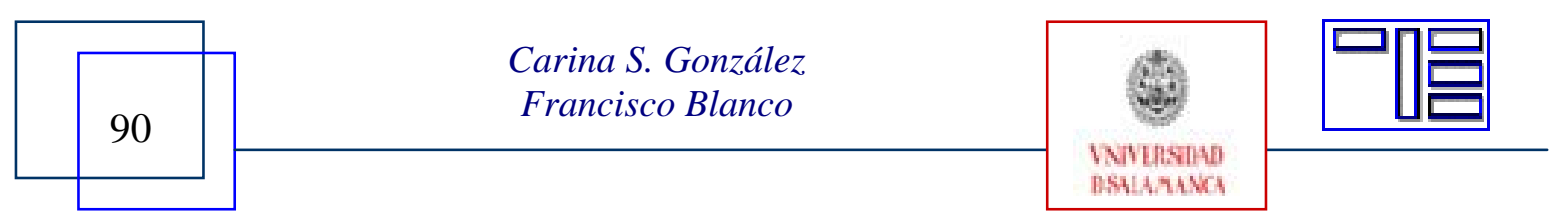


LEITE, J.C.S.P., HADAD, G.D.S., DOORN, J.H., KAPLAN, G.N., A Scenario Construction Process, Requirements Engineering Journal Vol.5, 2000.

LIU, L.; YU, E., From Requirements to Architectural Design - Using Goals and Scenarios, Proceedings first STRAW workshop, 2001.

MAGUIRE, M. (2001). Methods to support human-centred design. International Journal of Human-Computer Studies, 55, 587-634.

MARQUÉS, P. (2000), Las claves del éxito, Cuadernos de Pedagogía , 291, 55-58

Moreno L., González C.S., Castilla I., González E., Sigue F. (2007). "Use of Constructivism and Collaborative Teaching in an ILP Processors Course". IEEE Transactions on Education, Volumen: 2 (50). 101-111, 2007

PAIVA, A., editor (2000). Affective Interactions. Towards a New Generation of Computer Interfaces, Volume 1814 of Lecture Notes in Computer Science, Heidelberg. Springer-Verlag. Selected papers from (Affect in Interactions, 1999).

PICARD, R. W. (1997). Affective computing. Technical Report 321, M.I.T. Media Laboratory Perceptual Computing Section, Cambridge, Massachussetts.

REBOLLO CATALÁN, Ma A.; GARCÍA PÉREZ, R., BARRAGÁN SÁNCHEZ, R., BUZÓN GARCÍA, O., VEGA CARO, L. (2008). Las emociones en el aprendizaje online. RELIEVE, v. 14, n. 1. Consultado en http://www.uv.es/RELIEVE/v14n1/RELIEVEv14n1_2.htm el 26 de Septiembre de 2008.

RYAN, R. M., SCOTT RIGBY, C. and PRZYBYLSKI, A. (2006). The Motivational Pull of Video Games: A Self-Determination Theory Approach.

SERIE INFORMES del CNICE. Nro 2. Videojuegos y Educación. Consultado en http://ares.cnice.mec.es/informes/02/documentos/iv04_0102a.htm el 26 de Septiembre de 2008.

SHNEIDERMAN, B. (1992). Designing the user Interface: Strategies for effective human-computer interaction. Second Edition, Addison-Wesley, New York.,(1992)

SHNEIDERMAN, B. (1998): Designing the user interface. Reading MA: AddisonWesley.

SPIVAK, N. (2006) The Third-Generation Web is Coming. http://www.kurzweilai.net/meme/frame.html?main=/articles/art0689.html.

SQUIRE, K. (2006). From Content to Context: Videogames as Designed Experience. Educational Researcher.

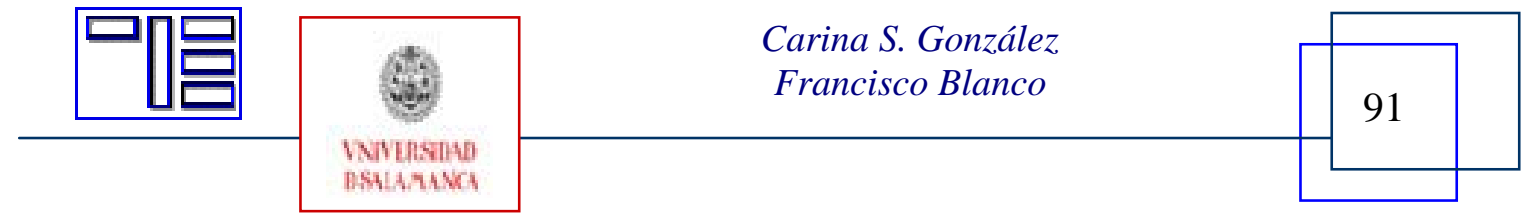


Revista Electrónica Teoría de la Educación.

Educación y Cultura en la Sociedad de la Información.

http://www.usal.es/teoriaeducacion

Para citar la presente editorial puede utilizar la siguiente referencia:

GONZÁLEZ, Carina S y BLANCO, Francisco (2008). Emociones con videojuegos: Incrementando la motivación para el aprendizaje. En SÁNCHEZ i PERIS, Francesc J. (Coord.) Videojuegos: una herramienta educativa del "homo digitalis" [monográfico en línea]. Revista Electrónica Teoría de la Educación: Educación y Cultura en la Sociedad de la Información. Vol. 9, $\mathrm{n}^{0}$ 3. Universidad de Salamanca [Fecha de consulta: $\mathrm{dd} / \mathrm{mm} /$ aaaa $]$.

http://www.usal.es/ teoriaeducacion/rev_numero_09_03/n9_03_gonzalez_blanco.pdf ISSN: 1138-9737 